\title{
Der Schutz des Privaten als internationales Grundrecht
}

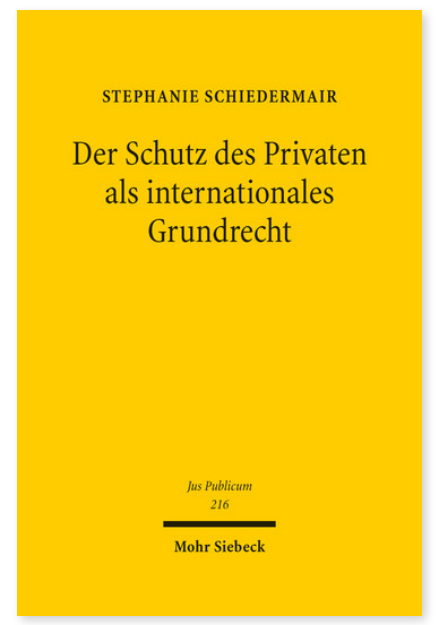

2012. XIII, 460 Seiten. JusPubl 216

ISBN 978-3-16-152164-5

DOI 10.1628/978-3-16-152164-5

eBook PDF 119,00€

ISBN 978-3-16-151936-9

Leinen $119,00 €$
Der Schutz des Privaten als internationales Grundrecht bietet einen umfassenden Überblick über die internationalen Regelungen und die internationale Rechtsprechung zum Thema Privacy. Im Gegensatz zum deutschen Verfassungsrecht formuliert das Völkerrecht den Schutz des Privaten als einheitliches Grundrecht. Die Auslegung dieses Grundrechts durch den Menschenrechtsausschuss der Vereinten Nationen thematisiert insbesondere den Schutz der Familie, etwa bei drohender Abschiebung eines Familienmitglieds, den Schutz der räumlichen Privatsphäre vor unbefugtem Eindringen, die Vertraulichkeit der Korrespondenz sowie private Handlungen, etwa homosexuelle Kontakte. Dieselben Grundthemen spiegeln sich in der Rechtsprechung des EGMR und des EuGH zum Schutz des Privaten wider. Stephanie Schiedermairs Analyse stellt damit auch die grundrechtliche Basis für zukünftige völkerrechtliche Verträge zum Schutz des Privaten vor.

Stephanie Schiedermair Geboren 1977; Studium der Rechtswissenschaften, Germanistik, Politikwissenschaften, Geschichte; 2004 Promotion; 2012 Habilitation; seit 2007 Akademische Rätin a. Z. an der Johannes Gutenberg-Universität Mainz; seit 2008 Dozentin im Weiterbildungsstudiengang Medienrecht des Mainzer Medieninstituts.

\section{Jetzt bestellen:}

https://mohrsiebeck.com/buch/der-schutz-des-privaten-als-internationales-grundrecht-9783161521645?no_cache=1 order@mohrsiebeck.com

Telefon: +49 (0)7071-923-17

Telefax: +49 (0)7071-51104 